\title{
Design and development of an automatic feeder for Penaeus vannamei culture
}

\author{
P. NILA REKHA, K. AMBASANKAR, S. STANLINE, K. SETHURAMAN, J. SYAMADAYAL, \\ A. PANIGRAHI AND KUMARAGURUVASAGAM \\ ICAR-Central Institute of Brackishwater Aquaculture, 75, Santhome High Road, R. A. Puram, Chennai - 600028 \\ Tamil Nadu, India \\ e-mail:rekha@ciba.res,nila_71@yahoo.com
}

\begin{abstract}
The introduction of Penaeus vannamei Boone, 1931, during 2009 opened up a new vista in Indian aquaculture. Presently, $90 \%$ of shrimp farming in the country is contributed by P. vannamei. The potential productivity level is around $10-12 \mathrm{tha}^{-1}$ and handling the feed during the course of culture increases considerably especially towards the end of culture period. This calls for automation in shrimp farming especially for feeding practices so that labour problem faced by the industry could be solved. The biosecurity requirement for vannamei farming can also be best met with the use of automatic feeders. The present study attempted designing and development of an indigenous automatic feeder for $P$. vannamei culture. The feeder design comprised four major components viz., feed hopper, distribution mechanism, a control unit for regulating the quantity and frequency of feeding and the power supply unit. Automation is effected through two timers with a digital display so that dispensing of the feed as well as duration of feeding could be easily adjusted by the farmers. Performance evaluation of the automatic feeder was done exhaustively and the results clearly showed that the maximum dispersion distance was $39 \mathrm{~m}$ dia and the maximum quantity of feed dispersed was $620 \mathrm{~g}$ in $5 \mathrm{sec}$. On farm evaluation of the feeder was also carried out in a shrimp pond and the installation height was optimised as approximately $75 \mathrm{~cm}-1 \mathrm{~m}$ from the water level for facilitating better dispersion of the feed.
\end{abstract}

Keywords: Automatic feeder, Brackishwater aquaculture, Design, Penaeus vannamei, Shrimp farming

\section{Introduction}

The major challenge in scientific shrimp farming is to provide artificial feeds in proper quantity at the right time as per requirement. It is a fact that the major operating cost in aquaculture, is the cost of feed which may account for $50 \%$ or more. Development of a high quality feed as well as the method of feeding are important since these influence the overall quantity of feed consumption, soil and water quality of the pond and eventually the success of the culture. Introduction of Penaeus vannamei through specific pathogen free (SPF) stock in 2009 opened up a new vista in Indian aquaculture and the seafood export from India crossed 1 million $\mathrm{t}$ for the first time and the export earnings crossed $\$ 4.5$ billion during 2013-14 (MPEDA, 2014). At present, $90 \%$ of the shrimp farming in the country is contributed by $P$. vannamei with the maximum allowed stocking density of 60 nos. $\mathrm{m}^{-2}$. The potential productivity is around $10-12 \mathrm{t} \mathrm{ha}^{-1}$ and handling the feed during the course of culture increases enormously especially during the end of culture period in case of $P$. vannamei. This calls for automation in shrimp farming especially with respect to feeding practices which would help in solving the labour problem faced by the industry.
Automatic feeders and feeding systems are playing a major role in the success of aquaculture farms globally and in the near future, it would become a necessity if intensive farming systems with more stocking density are to be adopted. Automatic feeders are found to be suitable for P. vannamei culture owing to its feeding behaviour which is a column dweller compared to tiger shrimp Penaeus monodon which is a bottom feeder. So far in P. monodon culture, the use of auto feeders is not common, with the feeding behaviour of the shrimp being the primary constraint. The application of different types of automatic feeding devices (Baldwin, 1983; Charlton and Bergot, 1986; Parker, 1989; Mohapatra et al., 2003) and different kinds of demand feeders (Rubio et al., 2004; Mohapatra et al., 2009) reported earlier are mostly for finfish farming. Various automatic feeders designed primarily for fish have been tried in shrimp ponds adopting intensive farming operations. Commercially many models are available in Asian countries like Thailand, China, Malaysia and Vietnam and mixed opinion exists about their application and performance. The farming community has debated the extensive comparisons between the efficiency of hand feeding in contrast to the automatic feeder. Although it cannot be stated with certainty that one method is more efficient than the other, the savings in labour realised by the use of automatic feeders 
are significant. Moreover, corporate farmers have already imported automatic feeders and using these at selected places. Since these feeders were developed elsewhere, the expected benefit could not be observed under Indian conditions. This emphasises the need for the development of indigenous automatic feeders suited to the farming of P. vannamei in the country.

The biosecurity requirement for $P$. vannamei farming could also be best met with the use of automatic feeders. Also, there are other potential advantages from the use of automatic feeders such as maintenance of better water quality, clear pond bottom and better feed conversion ratio (FCR). Feeding frequency is usually dependent on farm size, as well as the species and size of the species being cultivated. But mostly, it has been observed that to a greater extent, the feeding and feeding frequency depends on labour availability. Hence the present task was taken up with the main aim to design and fabricate an indigenous timer-controlled automatic pellet feeder unit and to evaluate its performance for the culture of $P$. vannamei. It is envisaged that the indigenous cost-effective feeder would help enhance the technical efficiency and adaptability of automatic feeding in farming of $P$. vannamei.

\section{Materials and methods}

\section{Design criteria}

A simple design of the automatic feeder comprises four major components viz., a feed hopper, mechanisms for feed distribution, an electrical power supply for the distribution mechanism and a control unit to regulate the distribution mechanism (Fig. 1). Each component needs to be designed with utmost care. Cost is the most important factor prohibiting wider adoption of automatic feeders and hence an energy efficient low-cost feeder with efficient delivery is the need of the hour. The material for the feeder assembly needs to be corrosion resistant and durable under the unavoidable

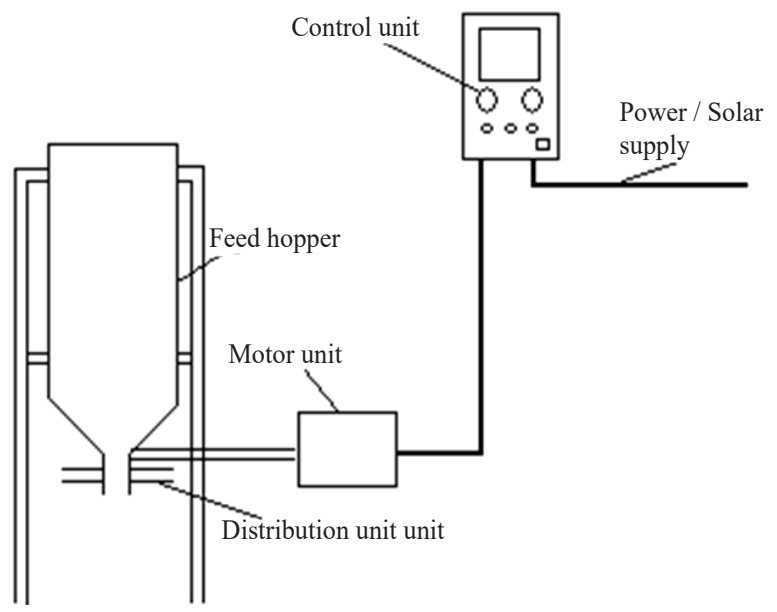

Fig. 1. Components of the feeder saline conditions of shrimp farms. The materials also need to be light and at the same time strong enough to face the windy conditions in the coastal area.

\section{Fabrication of the feeder}

The feeder designed and developed during the present study, is a simple, low-cost one which contains only standard, easily available parts and it is a timer-controlled automatic feeder (Fig. 2).

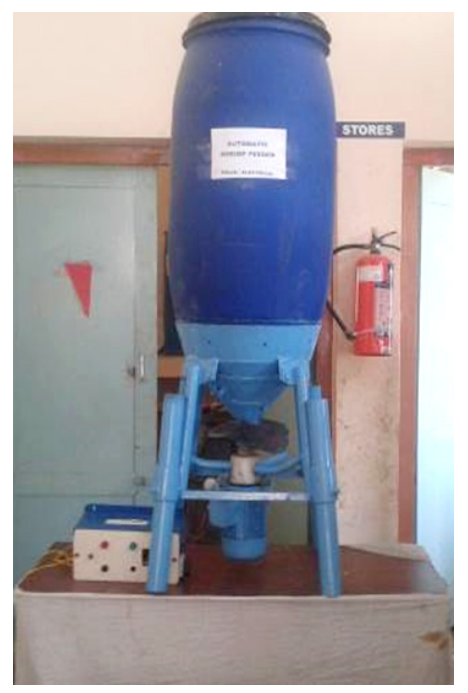

Fig. 2. Indigenously designed automatic feeder

\section{Feed hopper}

The feed hopper is basically a PVC drum of capacity $125 \mathrm{~kg}$. The material selection was done, considering the cost, saline conditions prevailing in shrimp farms and durability. The material needs to be rust free, should not react with the feed material and should have a long life and hence PVC was selected. The angle of inclination/repose plays an important role in the design of feeding devices such as demand feeders which rely on the gravitational force for feeding (Mohapatra, 2009). In the case of timer controlled automatic feeders, the distribution mechanism is more important. For facilitating feeding to the distribution system, the hopper bottom was designed with the greater angle of repose $\left(50^{\circ}\right)$ than the angle of repose of the materials to be dispensed $\left(44^{\circ}\right)$. The valve which controls the flow of feed as per the timer was designed in order to facilitate smooth operation. Prior to venturing in to design of the feed hopper, detailed engineering properties of the shrimp feed in the size range from 0.5 to $2.5 \mathrm{~mm}$ were studied. All aspects were taken care while designing to ensure the quality of the feed dispensed through the feeder, for e.g., to make sure that the feed is not broken when dispensed.

\section{Control unit}

Automation was effected through two timers (Fig. 3) with a digital display, set in such a manner that dispensing of 


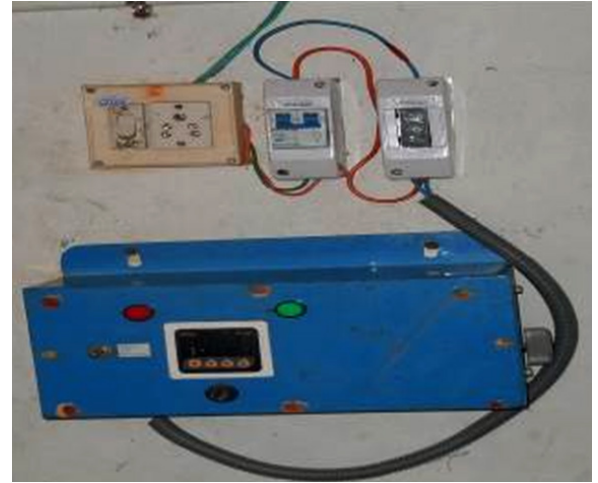

Fig. 3. Control unit - timer

the feed and the duration of feeding could be easily adjusted by the farmers.

\section{Distribution unit}

The distribution system was designed initially with four pipes fixed to the circular disc at the bottom of the feed hopper (Fig. 4.). It is powered by a $0.5 \mathrm{hp}$ series motor with an rpm of 2800. Adjustment can be made for variable speed to effect uniform dispersion. Series of trials were conducted with varying pipe diameter, pipe length at different motor speed

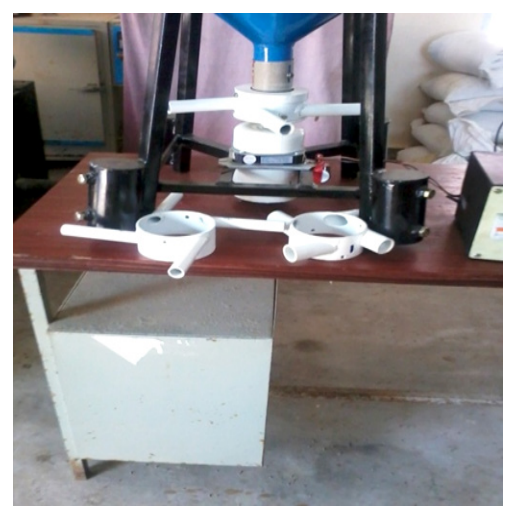

Fig. 4. Distribution system with four pipes

to investigate the quantity of feed dispensed and radius of influence. Based on the results, the design of the distribution system was modified with three pipes of uniform length $(175 \mathrm{~mm})$ and diameter $(20 \mathrm{~mm})$, having a $30^{\circ}$ inclination in the upward direction to facilitate wider dispersion of feed (Fig. 5).

\section{Performance evaluation}

A series of trials were conducted prior to arriving at the final design, especially to standardise the quantity of the feed dispensed, the radius of influence and uniformity in spreading as well as the height of installation. In this paper, only relevant parameters are discussed. A trial run of the

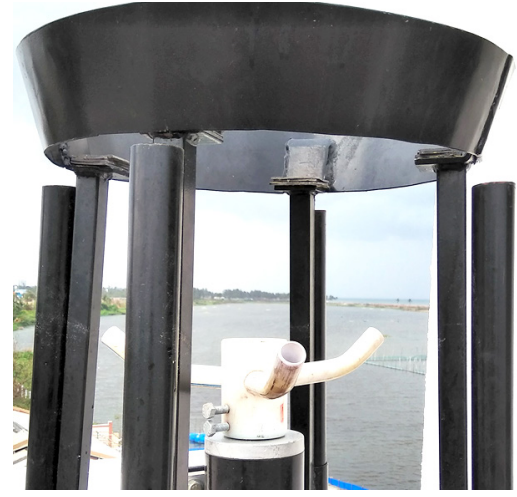

Fig. 5. Distribution system with three pipes

automatic shrimp feeder to determine the quantity of feed and the radius of influence of the pellet feed dispensed has been discussed in detail. For the above purpose, different speeds of the motor and height positions of the hopper were tested and the minimum as well as maximum distances of the pellets dispensed were recorded. The speed of the propeller was adjusted at 700, 1000 and $1400 \mathrm{rpm}$. Finally based on the results, the modified feeder was designed and installed at farmer's field and evaluated for on farm performance. The modified feeder was designed with motor of $2800 \mathrm{rpm}$ for increased dispersion width and a distribution system with 3 pipes to reduce the quantity of dispersion.

\section{Farmers'perception}

A structured questionnaire was prepared and the farmers' perception of the automatic feeder was assessed. The questionnaire also provided an opportunity for the farmers to rank the advantages and disadvantages of the system.

\section{Results and discussion}

Distribution system with four pipes

Evaluation of the distribution mechanism with four pipes revealed that the radius of influence ranged between 0.2 to $5.45 \mathrm{~m}$ (Table 1 ). The maximum radius of distribution of $5.5 \mathrm{~m}$ was observed for feed size of $2.5 \mathrm{~mm}$ at $1400 \mathrm{rpm}$ at a height of installation of $1.5 \mathrm{~m}$. Even for a height of installation of $1.5 \mathrm{~m}$ at $1400 \mathrm{rpm}$ for a feed size of $3 \mathrm{~mm}$, the distribution was observed to be $5.45 \mathrm{~m}$. It could be observed that at the higher heights of installation, the feed is distributed comparatively farther, as compared to the lower heights. It is obvious that more the height of installation, more the distribution distance, as reported by Yeoh et al. (2010) based on the performance evaluation of automatic fish feeder. But from the present study, it could be inferred that the motor speed is more important than the height of installation. Invariably at higher motor speed, the radius of distribution was found to be more for all sizes of 
Table 1. Initial performance evaluation with different feed sizes and height of installation

\begin{tabular}{lllllll}
\hline \multirow{2}{*}{ Height of installation $(\mathrm{m})$} & Size of feed $(\mathrm{mm})$ & Time $(\mathrm{sec})$ & Speed $(\mathrm{rpm})$ & \multicolumn{3}{c}{ Radius of dispersion $(\mathrm{m})$} \\
\cline { 5 - 7 } & & & & Min. & Max. & Average \\
\hline 1.5 & 1.8 & 2 & 750 & 0.3 & 3.5 & 1.9 \\
1.5 & 1.8 & 2 & 1000 & 0.3 & 4 & 2.15 \\
1.5 & 1.8 & 2 & 1400 & 0.4 & 4.2 & 2.3 \\
1.5 & 2.5 & 2 & 700 & 0.4 & 4 & 2.2 \\
1.5 & 2.5 & 2 & 1000 & 0.7 & 4.1 & 2.4 \\
1.5 & 2.5 & 2 & 1400 & 0.9 & 4.7 & 2.8 \\
1.5 & 3 & 2 & 750 & 0.5 & 4.3 & 2.4 \\
1.5 & 3 & 2 & 1000 & 0.5 & 4.1 & 2.3 \\
1.5 & 3 & 2 & 1400 & 0.5 & 5.45 & 2.975 \\
2.5 & 1.8 & 2 & 750 & 0.3 & 3 & 1.65 \\
2.5 & 1.8 & 2 & 1000 & 0.2 & 3.5 & 1.85 \\
2.5 & 1.8 & 2 & 1400 & 0.4 & 4 & 2.2 \\
2.5 & 2.5 & 2 & 750 & 0.35 & 3.8 & 2.075 \\
2.5 & 2.5 & 2 & 1000 & 0.35 & 4 & 2.175 \\
2.5 & 2.5 & 1400 & 0.5 & 5.5 & 3 \\
2.5 & 3 & 2 & 750 & 0.3 & 3.7 & 2 \\
2.5 & 3 & 2 & 1000 & 0.4 & 5 & 2.7 \\
2.5 & 3 & 2 & 1400 & 0.4 & 5.3 & 2.85
\end{tabular}

the feed tested. Moreover, the minimum radius of influence ranged from 0.3 to $0.9 \mathrm{~m}$. From this, it could be inferred that the variable speed motor would impact uniform distribution. From these observations, it was obvious that motor rpm needs to be increased for wider distribution. The quantity of feed distributed through this four pipe system was more for $3 \mathrm{sec}$ and it was about $2.3 \mathrm{~kg}$ (Table 2). Feed management in $P$. vannamei culture requires either continuous feeding or more feeding frequency which means less quantity to be dispersed and hence a three pipe distribution system was designed subsequently.

Modified distribution system with three pipes

The number of dispensing pipes was reduced to 3 , mainly to reduce the flow of feed. The 3 pipes were placed $120^{\circ}$ apart from each other in the distribution mechanism.
Each pipe was provided with an inclination of about $30^{\circ}$ in the upward direction to increase the dispensing width. The results of performance evaluation of modified distribution system with three pipes are given in Table 3. Since pellets of $2 \mathrm{~mm}$ are generally used under farming conditions, the performance evaluation of the modified distribution system was conducted only with $2 \mathrm{~mm}$ size feed. It could be observed from the table that the average feed quantity dispersed ranged from 110 to $620 \mathrm{~g}$ in $1-5 \mathrm{sec}$. The maximum diameter of dispersion (dispensing width) was about $39 \mathrm{~m}$ which covers up to $1194 \mathrm{~m}^{2}$ area.

Motor

To cater the needs of the shrimp ponds which are generally of $0.75-2$ ha area, the motor speed was increased to $2800 \mathrm{rpm}$. From Table 3, it could be noted that the feed

Table 2. Performance of distribution system with four pipes

\begin{tabular}{|c|c|c|c|c|c|c|c|}
\hline \multirow{2}{*}{ Motor rpm } & \multirow{2}{*}{ Spreading pipe dia $(\mathrm{mm})$} & \multicolumn{3}{|c|}{ Feed dispersed (g) } & \multicolumn{3}{|c|}{ Dispensing width (m) } \\
\hline & & $1 \mathrm{sec}$ & $2 \mathrm{sec}$ & $3 \mathrm{sec}$ & $1 \mathrm{sec}$ & $2 \mathrm{sec}$ & $3 \mathrm{sec}$ \\
\hline 700 & 15 & 90 & 220 & 400 & 4.3 & 7.1 & 7.4 \\
\hline 700 & 20 & 110 & 280 & 470 & 4.14 & 5.14 & 6.42 \\
\hline 700 & 25 & 470 & 1120 & 1640 & 3.56 & 3.6 & 5.5 \\
\hline 1000 & 15 & 210 & 450 & 690 & 8.2 & 9.2 & 9.2 \\
\hline 1000 & 20 & 220 & 490 & 870 & 6.1 & 9.5 & 11.1 \\
\hline 1000 & 25 & 880 & 1510 & 1980 & 5.8 & 6.4 & 7 \\
\hline 1400 & 15 & 490 & 970 & 1410 & 14 & 17 & 13.5 \\
\hline 1400 & 20 & 600 & 1170 & 1680 & 15 & 20 & 21.7 \\
\hline 1400 & 25 & 1340 & 1880 & 2370 & 15 & 19 & 18 \\
\hline
\end{tabular}


dispersed is about $620 \mathrm{~g}$ in $5 \mathrm{sec}$. The dispersion width is about $39 \mathrm{~m}$ in motor with $2800 \mathrm{rpm}$ whereas in motor with $1400 \mathrm{rpm}$ the dispersion width is only $21.7 \mathrm{~m}$ and it covers only $370 \mathrm{~m}^{2}$. The huge difference is due to change in the motor rpm and change in the distribution mechanism. Feed dispersed has been reduced more than $75 \%$ compared to the above table. So the design of spreading pipe distribution was refined with reduction of number of pipes to 3. A comparison of both Motor I of $1400 \mathrm{rpm}$ and Motor II of $2800 \mathrm{rpm}$ in terms of quantity of feed dispersed was done and results are presented in Table 4.

\section{Pipe diameter}

Pipe diameter is another important parameter in the design, since optimum pipe size will ensure the correct amount of feed to be dispensed. From Table 2, it could be clearly seen that at motor speed of $700 \mathrm{rpm}, 15 \mathrm{~mm}$ dia pipe effects the highest dispensing width of about $7.4 \mathrm{~m}$ and the total area of dispersion is $43 \mathrm{~mm}^{2}$. From the table, we can see that spreading pipe with a diameter of $20 \mathrm{~mm}$ (at motor speed

Table 4. Quantity of feed distributed employing the motors at different time durations

\begin{tabular}{lll}
\hline Time & Motor I $(1400 \mathrm{rpm})$ & Motor II $(2800 \mathrm{rpm})$ \\
\hline $1 \mathrm{sec}$ & $1.350 \mathrm{~kg}$ & $1.450 \mathrm{~kg}$ \\
$2 \mathrm{sec}$ & $1.950 \mathrm{~kg}$ & $1.800 \mathrm{~kg}$ \\
$3 \mathrm{sec}$ & $2.450 \mathrm{~kg}$ & $2.200 \mathrm{~kg}$ \\
$4 \mathrm{sec}$ & $2.900 \mathrm{~kg}$ & $2.500 \mathrm{~kg}$ \\
$5 \mathrm{sec}$ & $3.350 \mathrm{~kg}$ & $2.910 \mathrm{~kg}$ \\
\hline
\end{tabular}

of $1400 \mathrm{rpm}$ ) has the highest dispensing width of about $21.7 \mathrm{~m}$ which covers $370 \mathrm{~m}^{2}$. If the pipe size is small, the distribution distance is farthest but feed quantity will be less. Similarly, if the pipe diameter is more, the feed will fall close by and more quantity will be distributed. For better performance in shrimp farming ponds, which are generally around 1 ha area, the feed should be distributed uniformly covering more area at lesser quantity. Based on the results of the trials, pipe diameter of $20 \mathrm{~mm}$ was selected as ideal for $P$. vannamei culture.

\section{Pipe length}

The pipe length in the distribution system is another important parameter in the design, since optimum pipe length will help to dispense the correct amount of feed. If the pipe length is small, the distribution distance is small and if the length is more, wider area will be covered. Based on the trials, pipe length of $17.5 \mathrm{~cm}$ was chosen as ideal.

\section{Inclined pipes}

Trials conducted with straight and inclined pipes demonstrated clear difference, with inclined pipe throwing the feed at farthest distance. Due to the projectile motion of the feed dispersed, more distance is covered. However, with more inclination feed breakage was observed and hence inclination of $30^{\circ}$ in the upward direction (after $100 \mathrm{~mm}$ of the pipe length) was found to be ideal for maximum dispersion of quality feed with out breakage.

\section{Height of installation}

Based on the results of field trials, the optimum height of installation above the water level was arrived at approximately $80 \mathrm{~cm}$ to $1 \mathrm{~m}$, for better feed dispersion.

\section{Cost of fabrication}

The approximate cost (₹) for fabrication of the feeder is given in Table 5

Table 5. Fabrication cost (₹) of the feeder

\begin{tabular}{ll}
\hline Component & Cost (₹) \\
\hline Hopper & $1,000 /-$ \\
Timer unit with digital display & $9,000 /-$ \\
0.5 hp series motor with regulator & $2,000 /-$ \\
Installation of accessories, wires & $3,000 /-$ \\
Total cost & $15,000 /-$ \\
\hline
\end{tabular}

Farmers'perception

Results of the survey on farmers' perception indicated that the automatic feeder reduces the drudgery of the farm labourers and $89 \%$ farmers feel it is a necessity for shrimp farming. But some farmers still feel that manpower cannot be replaced as shrimp farming is a high risk enterprise and continuous monitoring is essential.

The change in the feeder motor $(2800 \mathrm{rpm})$, selection of ideal spreading pipe diameter $(20 \mathrm{~mm})$, reducing the number of spreading pipes to 3 instead of 4 and providing inclination $\left(30^{\circ}\right)$ to the spreading pipe led to reduction of the amount of feed dispersed and increase in the dispensing width of the feeder. This automatic shrimp feeder was found to be highly suitable for $P$. vannamei farms with water spread area ranging from 0.8 to 1 ha. This feeder is indeed a boon to the shrimp farmers as it is user friendly and can be operated with ease by the farmers.

The power crisis warrants the inclusion of alternative energy sources for operation of the automatic feeder which needs to be attempted. The scope of developing a solar powered UPS operated automatic feeder has been planned as a follow up to the present design.

\section{References}

Baldwin, W. J. 1983. The design and operation of an automatic feed dispenser. Aquaculture, 34: 151-155. 
Charlton, N. and Bergot, P. 1986. An improved automatic dry food dispenser for fish larvae. Prog. Fish Cult., 48: 156 -158.

Mohapatra, B. C., Sarkar, B. and Singh, S. K. 2003. Use of plastics in aquaculture. In: Satapathy, K. K. and Kumar, A. (Eds.), Plasticulture intervention for agriculture development in North-eastern region. ICAR Research Complex for NEH Region, Umiam, Meghalaya, p. 290-305.

Mohapatra, B. C. Sarkar, B., Sharma, K. K. and Majhi, D. 2009. Development and testing of demand feeder for carp feeding in outdoor culture system. Agricultural Engineering International: the CIGR E-journal. vol. XI.

MPEDA 2014. Annual report 2013-14. http://www.mpeda. gov.in/MPEDA/admin/app/webroot/files/annualreport/
1495802571MPEDAAnnualReport20132014.pdf (Accessed 24 December 2016)

Parker, N. C. 1989. Low cost automated feeder for fry and fingerlings. Prog. Fish Cult., 51: 42- 46.

Rubio, V. C., Vivas, M., Sanchez-Mut, A., Sanchez-Vazquez, F. J., Coves, D., Dutto, G. and Madrid, J. A. 2004. Self-feeding of European sea bass (Dicentrarchus labrax, L.) under laboratory and farming conditions using a string sensor. Aquaculture, 233(1-4): 393-403.

Yeoh, S. J., Taip, F. S., Endan, J., Talib, R. A. and Siti Mazlina, M. K. 2010. Development of automatic feeding machine for the aquaculture industry. Pertanika J. Sci. Technol., 18(1): 105-110. 